\title{
MMIC tuned front-end for a coherent optical receiver
}

Petersen, Anders Kongstad; Jagd, A. M.; Ebskamp, F.

Published in:

I E E E Photonics Technology Letters

Link to article, DOI:

10.1109/68.219709

Publication date:

1993

Document Version

Publisher's PDF, also known as Version of record

Link back to DTU Orbit

Citation (APA):

Petersen, A. K., Jagd, A. M., \& Ebskamp, F. (1993). MMIC tuned front-end for a coherent optical receiver. I E E E Photonics Technology Letters, 5(6), 679-681. https://doi.org/10.1109/68.219709

\section{General rights}

Copyright and moral rights for the publications made accessible in the public portal are retained by the authors and/or other copyright owners and it is a condition of accessing publications that users recognise and abide by the legal requirements associated with these rights.

- Users may download and print one copy of any publication from the public portal for the purpose of private study or research.

- You may not further distribute the material or use it for any profit-making activity or commercial gain

- You may freely distribute the URL identifying the publication in the public portal

If you believe that this document breaches copyright please contact us providing details, and we will remove access to the work immediately and investigate your claim. 


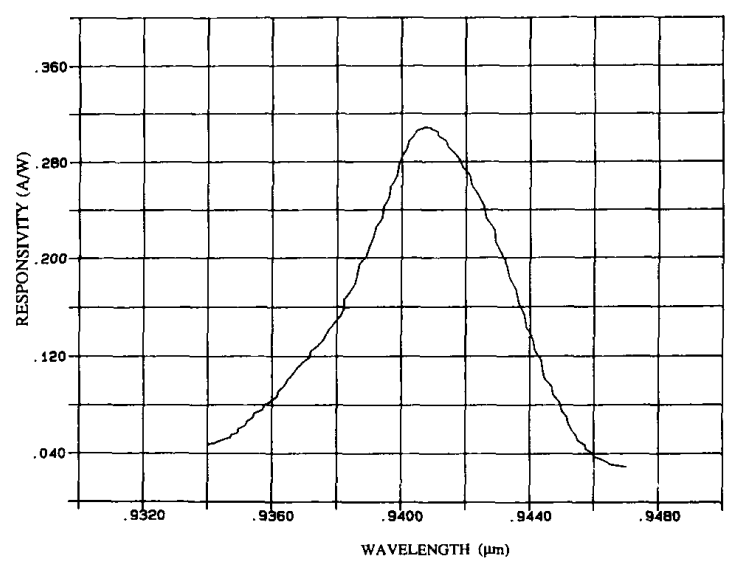

Fig. 4. The optical responsivity of the device in the HFET mode.

tor of the cavity is thus measured to be 162 . A recent model using energy balance considerations [6] predicts a cavity $Q$ of 500 and a quantum efficiency of $80 \%$ for the design used. The lower $Q$ of the cavity is attributed to a lower than expected reflectivity in the bottom stack.

In the BICFET mode, photocurrent is measured between the emitter and collector, with the source floating. The peak responsivity was measured to be $2.1 \mathrm{~A} / \mathrm{W}$ at a $V_{\text {ce }}$ of $-4 \mathrm{~V}$, with identical spectral characteristics to that obtained in the HFET mode.
In summary, an RCE inversion channel photodetector has been demonstrated in a structure suitable for integration with the DOES VCSEL.

\section{ACKNOWLEDGMENT}

The authors would like to acknowledge the assistance of D. Coult and D. Wendling in the deposition of the dielectric stack.

\section{REFERENCES}

[1] R. Kuchibhotla, A Srinivasan, J. C. Campbell, C. Lei, D. G. Deppe, Y. S. He, and B. Streetman, "Low-voltage high-gain resonant-cavity avalanche photodiode," IEEE Photon. Technol. Lett., vol. 3, Apr. 1991.

[2] R. P. Bryan, G. R. Olbright, W. S. Fu, T. M. Brennan, and J. Y. Tsao, "Near-infrared high-gain strained layer InGaAs heterojunction phototransistors: Resonant periodic absorption," Appl. Phys. Lett., vol. 59, no. 13, pp. 1600-1602, 1991.

[3] P. A. Evaldsson, S. Daryanani, P. Cooke, and G. W. Taylor, "An optoelectronic resonant cavity technology based on inversion channel devices," Opt. Quantum Electron., vol. 24, p. S133, 1992.

[4] S. Sargood, G. W. Taylor, T. Vang, P. Cooke, C. Burrus, B. Tell, and $\mathrm{K}$. Brown-Goebeler, "Operation of a single quantum well heterojunction field-effect photodetector," Appl. Phys. Lett., vol. 59, no. 16, pp. 1987-1989, 1991.

[5] K. Kishino, M. Ünlü, J. Chyi, L. Arsenault, and H. Morkoc, "Resonant-cavity enhanced (RCE) photodetectors," IEEE $J$. Quantum Electron., vol. 27, pp. 2025-2034, 1991.

[6] S. Daryanani and G. W. Taylor, "Theoretical and experimental results for a quantum well resonant cavity phototransistor," SPIE Proc. Physics and Simulation of Optoelectron. Devi. (Somerset, NJ), vol. 1679 , pp. $181-199,1992$.

\title{
MMIC Tuned Front-End for a Coherent Optical Receiver
}

\author{
A. K. Petersen, A. M. Jagd, and F. Ebskamp
}

\begin{abstract}
We present a low noise transformer tuned optical front-end for a coherent optical receiver. The front-end is based on a GaInAs /InP p-i-n photodiode and a full custom designed GaAs MMIC. To our knowledge this is the first time a transformer tuned MMIC is used in an optical front-end. The measured equivalent input noise current density is between 5-16 $\mathrm{pA} / \sqrt{\mathrm{Hz}}$ in the frequency range $5-14 \mathrm{GHz}$.
\end{abstract}

\section{INTRODUCTION}

$\mathrm{O}$ PTICAL communication systems based on coherent heterodyne detection have been reported in the literature during the last ten years. The application of coherent detection has, e.g., been suggested for long-haul and multichannel optical communication systems [1], [2].

Manuscript received January 5, 1993; revised March 19, 1993.

The authors are with Center for Broadband Telecommunications, Electromagnetics Institute, Technical University of Denmark, DK-2800 Lyngby, Denmark.

IEEE Log Number 9209614.
A coherent receiver is more complicated than a direct detection receiver, so in order for coherent systems to feature low cost, high reliability and low power consumption, a high degree of integration should be used. In this letter a front-end for a coherent heterodyne optical receiver is presented. The front-end is based on a commercially available GaInAs/InP $\mathrm{p}-\mathrm{i}-\mathrm{n}$ photodiode [3] and a full custom designed GaAs MESFET MMIC using the commercial F20 GaAs process, with an $f_{T}=20 \mathrm{GHz}$, from GEC Marconi [4]. The GaAs MESFET technology was chosen because of the low cost.

The required bandwidth of a coherent receiver is approximately two times the bit rate, which at high bit rates puts a very stringent demand on the front-end. Different types of front-end topologies have been proposed for coherent heterodyne receivers, based on either hybrid amplifiers [5], [6] or monolithic amplifiers [7].

Transformer tuned front-ends have both theoretically [8] and experimentally [9] been shown to be applicable in wideband heterodyne receivers. In the tuned front-end 
the parasitic capacitances in photodiode and FET's become part of the tuning circuit. The tuning decreases the thermal noise considerably compared to no tuning, and so reduces the local oscillator power needed to approach shot noise limited sensitivity.

Front-ends have been published with both single and balanced photodiodes [5]-[7]. The use of a balanced frontend design, using two photodiodes, tends to increase the equivalent input noise, due to the doubling of the photodiode parasitics. It has been confirmed by earlier work on hybrid single-end and balanced hybrid front-ends, that by careful design of the input tuning network, bandwidths of up to $15 \mathrm{GHz}$ can be achieved in both cases [9], [10]. A single photodiode has been chosen in this paper in order to demonstrate the principle of the noise tuning in a MMIC front-end.

\section{FRONT-END DESIGN}

A simplified schematic of the front-end is shown in Fig. 1. The transformer tuning is realised as a T-equivalent circuit. The inductors in the tuning circuits are formed by bond wires where the diode and the MMIC are interconnected and by spiral inductors on the MMIC. Because the inductors in the tuning circuits are resonating with the parasitic capacitances in the photodiode and the FET's, one has to be very careful with the design to avoid instabilities. This is especially important for the MMIC since no further adjustments are possible when the chip is manufactured. However, since the electrical properties of the inductive elements such as spiral inductors are determined by their geometry, they are highly reproducible when integrated on an MMIC. The use of via holes on-chip is also very important, because ground connections are well defined, with negligible parasitic inductance.

Fig. 2 shows a schematic drawing of the front-end layout. The photodiode was mounted on a separate carrier and modeled using one and two port $S$-parameter measurements [11]. The MMIC on the right hand side of Fig. 2 measures $1 \mathrm{~mm}$ by $2 \mathrm{~mm}$. The power supplies are decoupled on-chip as well as externally with $1 \mathrm{nF}$ Dicap capacitors. Smaller $10 \mathrm{pF}$ Dicap capacitors are used as dc blocks.

\section{Simulations AND Measurements}

The simulations and measurements are divided into two steps. The first step is the electrical characterisation of the MMIC, the second step is the optical characterisation of the front-end. Both the $S$-parameters of the MMIC and the front-end transimpedance and equivalent input noise current density were simulated using the microwave simulator Libra from EEsof. The front-end simulations are based on the photodiode model mentioned above and the MMIC was modeled using the component models offered by the foundry service [4]. The equivalent input noise current density and the transimpedance were simulated using the method presented in [12].

As a first step, the $S$-parameters of the MMIC alone were simulated and compared to measurements. The $S$ -

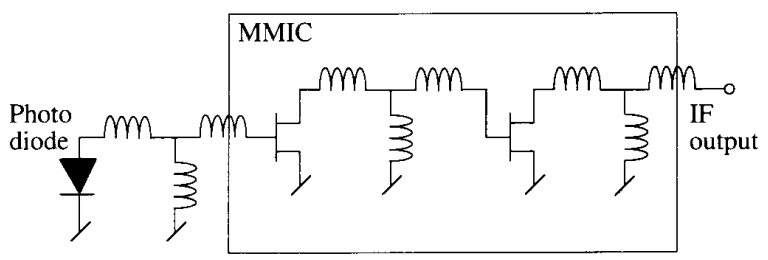

Fig. 1. Simplified schematic diagram of tuned front-end.

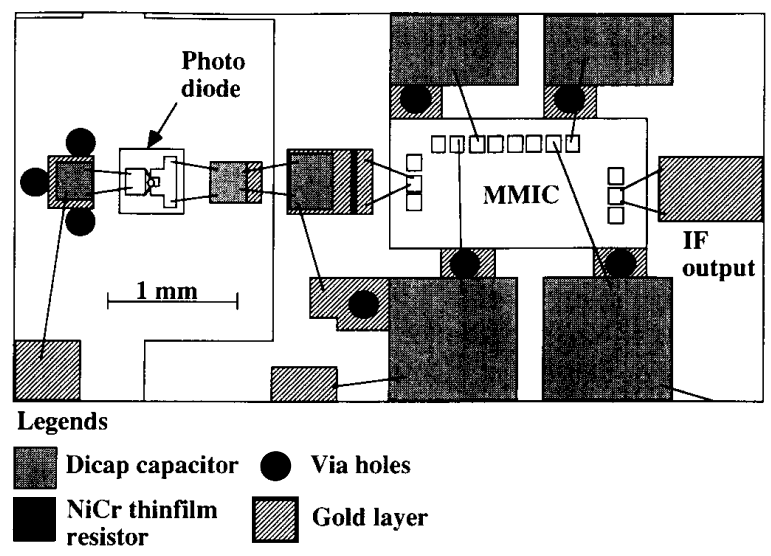

Fig. 2. Layout of mounted photodiode and MMIC. The components are mounted on alumina thinfilm substrate.

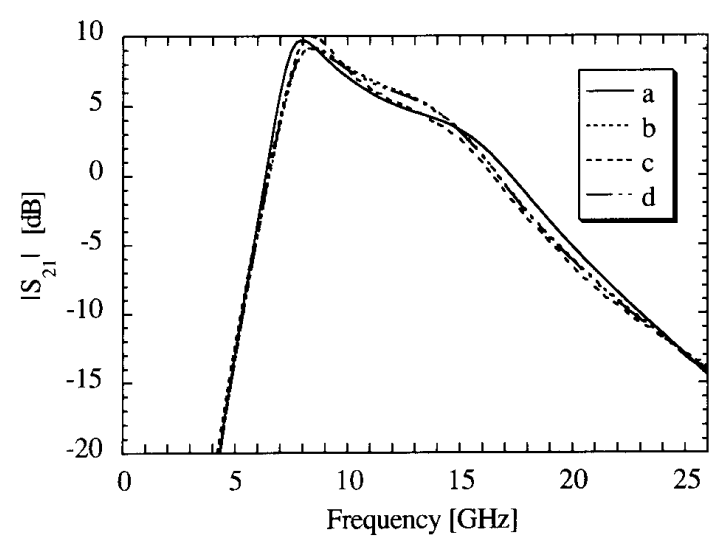

Fig. 3. Comparison between simulated and measured $\left|S_{21}\right|$. The Libra circuit simulator from EEsof was used for the simulations and the $S$-parameters were measured on-wafer with Cascade Microtech probes. (a) simulated, (b)-(d) measured sample 1-3, respectively.

parameters of the MMIC chips were measured on-wafer using a Cascade Microtech probe station and an HP8510B network analyser in the frequency range from $100 \mathrm{MHz}$ to $26 \mathrm{GHz}$. The simulated $\left|S_{21}\right|$ is shown in Fig. 3 as a solid curve and the measured $\left|S_{21}\right|$ is shown for three different chip samples. The three measured chips were randomly selected out of ten chips received from the foundry. All the received chips came from one wafer. It is observed from this figure that excellent agreement has been obtained between the simulations and the measurements. Also, there is very little difference between the individual 
chips, indicating that the components variations only have a moderate influence on the $S$-parameters. The maximum difference between measured and simulated $\left|S_{21}\right|$ is less than $2 \mathrm{~dB}$ up to $26 \mathrm{GHz}$.

The next step was the characterisation of the complete front-end. Both the transimpedance and equivalent input noise current density have been measured. The transimpedance was measured with a spectrum analyzer, calibrated with a reference diode. During the transimpedance measurement the photodiode is illuminated with a heterodyne beat signal between two lasers, one laser is fixed the other is swept to generate an IF signal at the output of the photodiode in the frequency range from 0 to $18 \mathrm{GHz}$. The equivalent input noise current density was found by measuring the noise spectrum at the output of the frontend and transforming the spectrum to the input of the front-end by using the measured transimpedance.

Two transimpedance simulations were made. The first transimpedance simulation was entirely based on the foundry models for the MMIC (Fig. 4, curve a), the second transimpedance simulation was based on the $S$ parameter measurements from MMIC sample 1 (Fig. 4, curve $b$ ). These two simulations are shown together with the measured transimpedance of the complete front-end in Fig. 4. The expected transimpedance based on the $S$-parameter measurements was $42-44 \mathrm{~dB} \Omega$ in the frequency range 6-12 $\mathrm{GHz}$. However, the measured transimpedance of the front-end is in the range 36-42 $\mathrm{dB} \Omega$ over the same frequency range. The three transimpedance curves in Fig. 4 indicate that the most difficult task is to predict the performance of the interconnection between the photodiode and the MMIC, while the transimpedance curves for the front-end with modeled and measured MMIC are in very close agreement. The measured transimpedance ripple is $\pm 3 \mathrm{~dB}$, with frequency characteristics similar to the simulations. This value is relatively large, due to the fact that only two stages were used. This ripple could be improved in a design with more transistor stages. This would have little influence on the equivalent input noise.

Curves $d$ and $e$ in Fig. 4 show the simulated and measured equivalent input noise current spectral density, respectively. The expected noise current density was 10-16 $\mathrm{pA} / \sqrt{\mathrm{Hz}}$ in the frequency range $6-12 \mathrm{GHz}$. An equivalent input noise current spectral density as low as 5-16 pA $\sqrt{\mathrm{Hz}}$ was achieved in the frequency range 5-14 GHz. This is the lowest value for MMIC front-ends in this frequency range reported to date, and comparable to the best reported noise values of hybrid front-ends [5], [6], [9].

\section{CONCLUSIONS}

A tuned front-end based on a GaAs MESFET MMIC and a PIN photodiode is presented. The equivalent input noise current spectral density of the front-end was 5-16 $\mathrm{pA} / \sqrt{\mathrm{Hz}}$ in the frequency range $6-12 \mathrm{GHz}$, and the transimpedance was in the same frequency range 36-42 $\mathrm{dB} \Omega$. The employment of a MMIC in a tuned optical front-end has been demonstrated. Less than $2 \mathrm{~dB}$ devia-

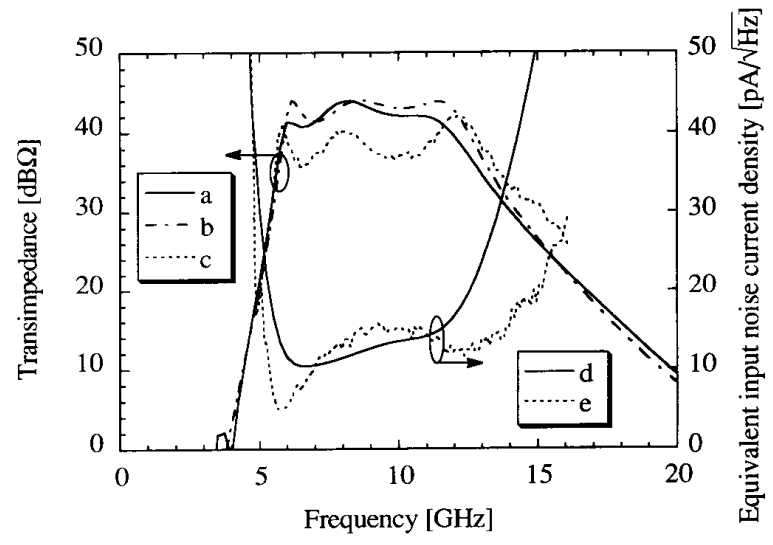

Fig. 4. Comparison between simulations and measurements. (a) Entirely simulated transimpedance; (b) simulated transimpedance based on measured MMIC $S$-parameters; and (c) measured transimpedance. (d) Simulated equivalent input noise current density and (e) measured equivalent input noise current density.

tion between simulated and measured results of the monolithic part of the front-end was obtained. The introduction of bondwire tuning between the photodiode and the MMIC resulted in a $6 \mathrm{~dB}$ deviation. A high degree of integration not only lowers the costs, but the performance of a MMIC is much more predictable than a hybrid design. We believe that tuned front-ends are very attractive in coherent heterodyne receivers if further integration is introduced.

\section{REFERENCES}

[1] S. Ryu, S. Yamamoto, H. Taga, N. Edagawa, Y. Yoshida and H Wakabayashi, "Long-haul coherent optical fiber communication systems using optical amplifiers," J. Lightwave Technol., vol. 9, pp. $251-260,1991$.

[2] L. Kazovsky and G. Jacobsen, "Multichannel CPFSK coherent optical communications systems," J. Lightwave Technol., vol. 7, pp. 972-982, 1989.

[3] D. Wake, R. Walling, and I. Henning, "Planar-junction, top-illuminated GaInAs/In PIN photodiode with bandwidth of $25 \mathrm{GHz}$," Electron. Lett., vol. 25, pp. 967-968, 1989.

[4] GaAs IC Foundry Design Guide, The GEC-Marconi Company plc, 1991.

[5] N. Ohkawa, "20 GHz low-noise HEMT preamplifier for optical receivers," in Proc. ECOC, vol. 1, Brighton, 1988, pp. 404-407.

[6] J. L. Gimlett, "A new low noise $16 \mathrm{GHz}$ PIN/HEMT optical receiver," in Proc. ECOC, vol. 2, Brighton, 1988, pp. 13-16.

[7] N. Takachio, "A $10 \mathrm{Gbit/s}$ optical heterodyne detection experiment using a $23 \mathrm{GHz}$ bandwidth balanced receiver," in Proc. IEEE MTT Symp. Dallas, TX, 1990, paper C-2, pp. 149-151.

[8] G. Jacobsen, J.-X. Kan and I. Garrett, "Tuned front-end design for heterodyne optical receivers," J. Lightwave Technol., vol. 7, pp. 105-114, 1989.

[9] F. Ebskamp, G. Schiellerup, and M. Hogdal, “A 7-13 GHz lownoise tuned optical front-end amplifier for heterodyne transmission system application," in Proc. IEEE MTT Symp., Boston, MA, 1991, paper T-3, pp. 585-588.

[10] F. Ebskamp, R. J. S. Pedersen, and G. Schiellerup, "A balanced 6-15 GHz low-noise tuned optical front-end for multi-gigabit-persecond heterodyne system application," in Proc. CLEO, Anaheim, CA, 1992, paper CTuL5, pp. 172-174.

[11] F. Ebskamp, "Wide bandwidth optical receiver front-end design and CPFSK system experiments at bit rates up to $5 \mathrm{Gbits} / \mathrm{s}$," Ph.D. thesis, Electromagnetics Institute, Tech. Univ. Denmark, LD 97, 1992.

[12] M. Hogdal, "New, simple method for simulating optical front end receivers," Electron. Lett., vol. 29, pp. 187-188, 1993. 